\title{
BMJ Open A cross-sectional study of the effect of health literacy on diabetes prevention and control among elderly individuals with prediabetes in rural China
}

\author{
Lulu Qin, Huilan Xu
}

To cite: Qin L, Xu H. A cross-sectional study of the effect of health literacy on diabetes prevention and control among elderly individuals with prediabetes in rural China. BMJ Open 2016;6:e011077.

doi:10.1136/bmjopen-2016011077

- Prepublication history for this paper is available online. To view these files please visit the journal online (http://dx.doi.org/10.1136/ bmjopen-2016-011077).

Received 8 January 2016 Revised 14 April 2016 Accepted 26 April 2016

CrossMark

Department of Social Medicine and Health Management, Xiangya School of Public Health, Central South University, Changsha, Hunan, China

Correspondence to

Huilan Xu;

xhl6363@126.com

\section{ABSTRACT}

Objectives: This study was designed to examine the effect of health literacy on diabetes prevention and control and risk factors for low diabetes health literacy among elderly individuals with prediabetes in rural areas in China.

Design setting and participates: A cross-sectional survey was conducted among elderly individuals in rural communities in Yiyang City in China. Multi-staged cluster random sampling was used to select 42 areas and 434 individuals with prediabetes who were interviewed using a questionnaire on diabetes health literacy in China.

Main outcome measures: Participants were asked for general information (age, gender, marital status, history of hyperglycaemia, family history of diabetes mellitus, presence of other diseases and level of education). Binary logistic regression analysis was used to identify risk factors for poor health literacy concerning diabetes prevention and control among elderly subjects with prediabetes.

Results: The median health literacy score for diabetes prevention and prediabetes control was 10.0 (IQR 7.013.0). The level of diabetes health literacy among men was lower than among women (OR 2.831, 95\% Cl 1.818 to 4.408), and lower among respondents with 1-6 years of education than among those with 6 years or more of education (OR 14.274, 95\% CI 5.927 to 34.375 ). Those with less than 1 year of education had the lowest literacy (OR $31.148,95 \% \mathrm{Cl} 11.661$ to 83.204 ). The level of diabetes health literacy among elderly individuals with prediabetes but no history of hyperglycaemia was lower than among those with a history of hyperglycaemia (OR $2.676,95 \% \mathrm{Cl} 1.101$ to 6.504 ).

Conclusions: Health literacy concerning diabetes prevention and control among elderly individuals with prediabetes was very low in rural China. Appropriate health education for elderly individuals with low educational levels should be incorporated into diabetes prevention efforts.

Trial registration number: ChiCTR-IOR-15007033; Results.

\section{INTRODUCTION}

Diabetes mellitus is a threat to public health worldwide $^{12}$ as the global prevalence of
Strengths and limitations of this study

- This is the first study to examine health literacy regarding diabetes prevention and control among an elderly population with prediabetes in rural China or other countries.

- The study provides valuable information on diabetes prevention and control among the elderly population with prediabetes in rural communities.

- The study is limited by its cross-sectional design and self-reported data.

diabetes and prediabetes are rapidly increasing. During the past 30 years, the prevalence of diabetes and prediabetes in China has also increased as Chinese people have changed their lifestyles following rapid economic development. ${ }^{3}$ The prevalence of diabetes and prediabetes in China in 2007-2008 were estimated to be $9.7 \%$ (92.4 million adults) and $15.5 \%$ (148.2 million adults), respectively. ${ }^{4}$ Prediabetes is an intermediate state of hyperglycaemia characterised by glycaemic parameters above normal levels but below the diabetic threshold; prediabetes is also called 'borderline diabetes'. There are three types of prediabetes: impaired fasting glucose (IFG), impaired glucose tolerance (IGT), and IFG combined with IGT. Prediabetes is strongly associated with an increased risk of developing type 2 diabetes (T2DM), stroke and cardiovascular diseases. ${ }^{5}$

The occurrence of diabetes and prediabetes increases with age, especially in the elderly (defined here as adults aged 60 years and above). Approximately 52\% of diabetes-attributable mortality worldwide occurs among the elderly. ${ }^{6}$ In North America and the Caribbean, the elderly accounted for $63 \%$ of patients with diabetes ${ }^{6}$ and $86 \%$ of all annual diabetes-related deaths in $2007 .^{7}$ In China, more than $20 \%$ of the elderly 
population in both urban and rural areas have prediabetes. ${ }^{4}$ Without timely and effective intervention, prediabetes is very likely to progress to diabetes within 10 years. $^{8}$

If one third of the nearly 150 million Chinese residents with prediabetes transition to T2DM over the next 6 years, this will result in a huge burden on the public health system.

Health literacy is the degree to which individuals have the capacity to obtain, process and understand the basic health information and services needed to make appropriate health decisions. Health literacy may be an important non-clinical factor that may decrease the risk of adverse outcomes. ${ }^{9}{ }^{10}$ Diabetes health literacy is associated with diabetes-related knowledge, and adequate health literacy is highly correlated with a better understanding of health education. ${ }^{11}$ Health literacy is a predictor of the utilisation of preventive healthcare. As reported previously, health literacy mediates the relationship between education and glycaemic control in low-income patients with diabetes. ${ }^{12}$ Moreover, health literacy is associated with disease-related knowledge, a requisite level of which is necessary for effective behaviour change. ${ }^{13}{ }^{14}$ People with a high level of health literacy are more likely to engage in health-promoting behaviours and therefore have better health outcomes. ${ }^{15}$

However, low health literacy is common. Approximately $55 \%$ of patients with diabetes in the USA have inadequate literacy, ${ }^{16}$ and Korean immigrants with low health literacy are at a greater risk of T2DM. ${ }^{17}$ People with low health literacy usually have less diseasespecific knowledge, a lower quality of life, and poorer health-related outcomes. They may also have trouble reading prescriptions, following medical instructions, and interacting with the healthcare system. ${ }^{18-20}$ Because of the link between health literacy and diseases, health literacy is important as regards the rapidly developing public health sector worldwide. ${ }^{21}$

In China, few studies have investigated diabetes health literacy among rural residents, and no epidemiological information is available on health literacy regarding prediabetes prevention and control among the rural elderly. Through a community-based study, we investigated health literacy relevant to diabetes prevention and control among rural elderly individuals in China. Our aim was to identify the factors associated with health literacy relevant to diabetes prevention and control and to provide scientific recommendations for diabetes prevention in the future.

\section{MATERIALS AND METHODS}

\section{Sample size calculation}

Sample size was calculated using the formula for crosssectional studies: $\alpha=0.05, \mathrm{n}=\mathrm{u} \alpha / 22 \mathrm{P}(1-\mathrm{P}) / \mathrm{d} 2$, where $\mathrm{u}=1.96$ when $\alpha=0.05, \mathrm{P}$ is the prevalence of prediabetes (which is $20 \%$ in this study), and $\mathrm{d}$ is admissible error (which was $4 \%$ here). The theoretical sample size was 423 which includes an extra $10 \%$ to allow for subjects lost during the study. Our initial investigations revealed there were about 10 elderly subjects with prediabetes in each village, so a total of 42 villages were required.

\section{Study population and procedures}

We used a multistage cluster randomised sampling method to select a representative sample of the rural population with prediabetes between April and July 2015; 'cluster' here refers to the village. Subjects were aged 60 years and over and from the rural areas of Yiyang City in Hunan province. In the first stage, sampling was stratified according to geographical characteristics, and two (Yuanjiang and Nanxian) out of six counties were selected. In the second stage, two (Yangluozhou, Yinfengqiao) out of 11 townships, and two (Qingshuzui, and Maocaojie) out of nine townships were randomly selected. In the third stage, $25 \%$ of rural villages were randomly selected from each chosen township (each township contains 30-50 villages). In the final stage, all households with elderly individuals in each selected village were identified.

Participants diagnosed as having prediabetes using oral glucose-tolerance tests (OGTTs) were enrolled in the study. The diagnostic standards for prediabetes as stated in the 1999 WHO criteria were applied. ${ }^{22}$ The elderly resident population (those who had lived in the area for 3 years or longer) who met the diagnostic standards for prediabetes were eligible to participate. Those with severe physical or mental illness were excluded from the study. Individuals who had diabetes or who met the diagnostic standards for diabetes were also excluded from the study. Our trained interviewers visited the elderly subject's home to carefully explain the study and its benefits and the rights of participants. All elderly subjects were invited to have an OGTT and undergo various measurements (blood pressure, height, weight and waist circumference). Participants were then interviewed face to face after giving written, informed consent. If the participant was illiterate, the consent form was signed by a family member. The elderly could decline to participate in the study without penalty, and could drop out at any time during the investigation.

There were 3197 elderly residents in the 42 selected areas (3068 individuals with permanent residence and 129 individuals who had lived for more than 3 years in the area but who had not achieved permanent residence). Of these, 603 had moved away, 336 were excluded because of physical or mental illness, and 114 of the remainder $(114 / 2258,5.0 \%)$ were excluded because they refused to take the OGTT, resulting in a screening sample of 2144 people. There were no difference in age, sex, marital status or education among those who participated in the OGTT compared to those who refused. Screening identified 461 elderly individuals with prediabetes. For various reasons, 21 of those with prediabetes were not investigated (figure 1), 


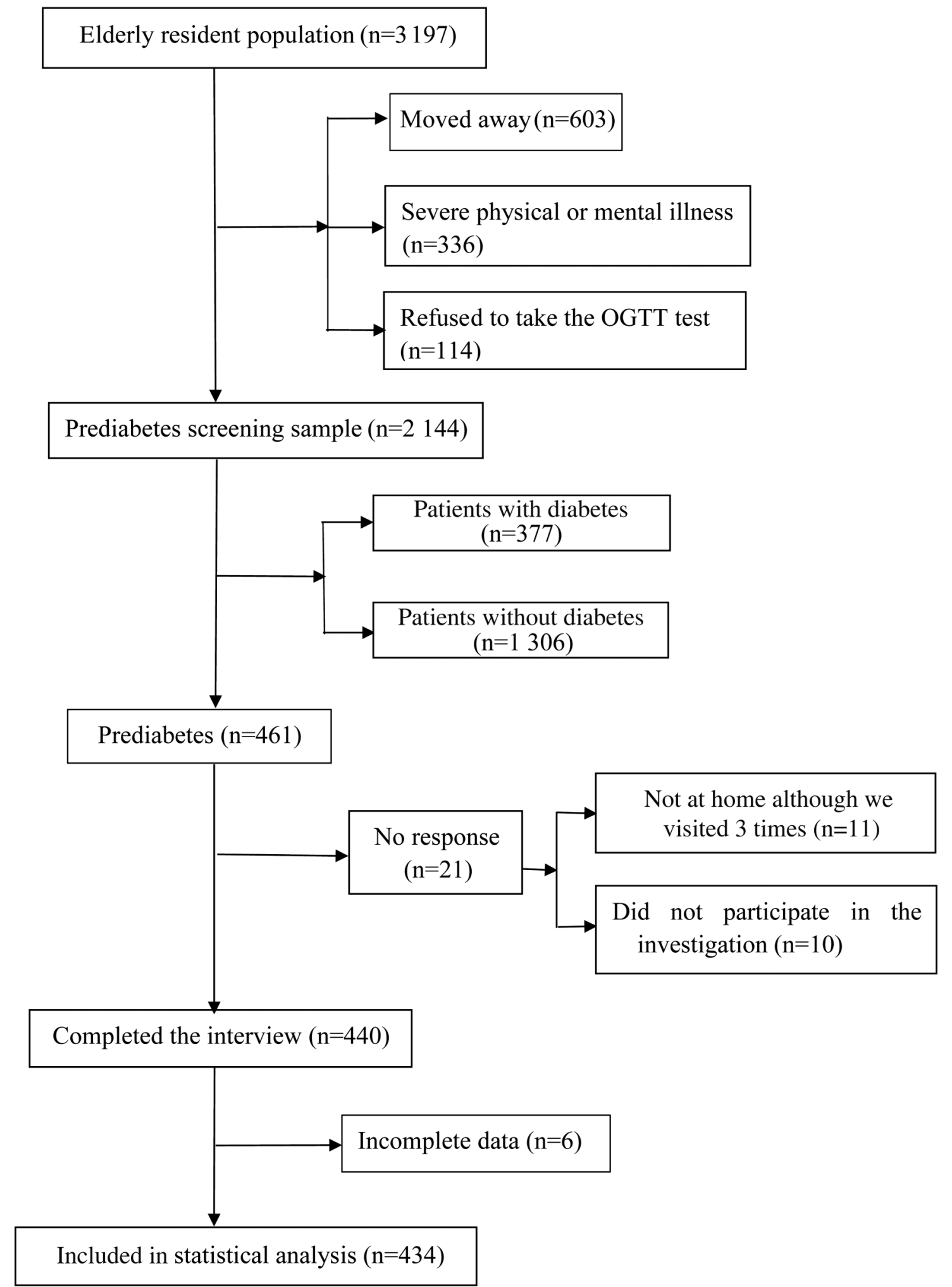

Figure 1 Response of Ssubjects enrolment flowchart. OGTT, oral glucose-tolerance test.

leaving 440 for investigation (440/461, 95.4\%). Six of the 440 individuals were excluded for incomplete data, so 434 elderly subjects underwent statistical analysis $(434 / 461,94.1 \%)$. A total of 434 individuals with prediabetes from of 42 rural villages were included in our study.
Data collection and measurements Prediabetes screening

Participants were instructed to maintain their usual physical activity and diet for a minimum of 3 days before the OGTT. After overnight fasting of at least 10 hours, each participant consumed a standard $75 \mathrm{~g}$ glucose solution. 
Blood was sampled at 0 and $120 \mathrm{~min}$ after consumption to measure glucose levels. The venous blood was collected from each participant into a vacuum tube containing sodium fluoride and used to measure glucose levels. Blood samples were stored at $-80^{\circ} \mathrm{C}$ and analysed for blood glucose $(\mathrm{mmol} / \mathrm{L})$ for no more than 1 hour. Each participant consumed a standard $75 \mathrm{~g}$ glucose solution, and blood was sampled at 0 and 120 min later to measure glucose levels. The level of plasma glucose was measured using a hexokinase enzymatic method, and serum cholesterol and triglyceride levels were assessed enzymatically with commercially available reagents in the biochemical laboratory of the primary care centre in each village. Fasting plasma glucose was analysed enzymatically using an Olympus AU640 autoanalyzer (Olympus, Kobe, Japan). All laboratories had successfully completed a standardisation and certification programme. Subjects with prediabetes diagnosed according to the 1999 WHO criteria ${ }^{22}$ were categorized into the following groups: (1) an IFG group with fasting plasma glucose of $6.1-7.0 \mathrm{mmol} / \mathrm{L} \quad(110-126 \mathrm{mg} / \mathrm{dL})$ and a 2-hour post-glucose load of $<7.8 \mathrm{mmol} / \mathrm{L}(140 \mathrm{mg} / \mathrm{dL})$; (2) an IGT group with a 2-hour post-glucose load of 7.8-11.1 mmol/L (140-200 mg/dL) and fasting plasma glucose of $\leq 6.1 \mathrm{mmol} / \mathrm{L}(110 \mathrm{mg} / \mathrm{dL})$; and (3) an IFG + IGT group.

\section{Socio-demographic information}

Socio-demographic information collected included age, gender, marital status, history of hyperglycaemia, family history of diabetes mellitus, presence of other diseases and education. Education was assessed by asking participants to select their highest level of education completed from the following choices: less than 1 year, 1-6 years, and 6 years and above.

\section{Health literacy on diabetes prevention and control}

Health literacy concerning diabetes prevention and control was assessed using the Questionnaire of Health Literacy of Diabetes Mellitus of the Public in China designed by the Chinese Center for Health Education. The questionnaire assessed diabetes-related knowledge, diabetes-related behaviour, and the acquisition and utilisation of diabetes information. This questionnaire has a high reliability and validity with a Cronbach's $\alpha$ of 0.866 .

The diabetes-related knowledge section assessed attitude to diabetes (eight questions), typical symptoms of diabetes (four questions), complications of diabetes (seven questions), factors conferring a high risk of developing diabetes (six questions) and methods to prevent diabetes (four questions); participants were given a score of 1 for a correct answer and 0 for a wrong answer. The diabetes-related behaviour section contained questions on the amount of time spent sitting each day, the frequency of exercise and physical examination, the regularity of daily diet, diet control and type of daily diet, current smoking status and current consumption of alcohol. Sitting for than less than 6 hours each day, exercising more than 3 times a week, consuming a regular daily diet, paying attention to diet control, preferring a bland diet, having a physical check-up more than once a year, not smoking, and not drinking or drinking little or occasionally were defined as good diabetes-related behaviours.

Five questions inquired about the acquisition and utilisation of diabetes information: (1) How much do you know about diabetes (a lot, a little, nothing); (2) Does your knowledge about diabetes meet your requirements? (yes, no); (3) Do you find it difficult to finding diabetesrelated information (no, slightly, very, haven't tried); (4) Do you understand diabetes-related information (understand well, cannot understand, have not tried to find any diabetes-related information); and (5) Are you able to identify diabetes-related information (yes, no, haven't tried to find diabetes-related information). People who knew a lot about diabetes and considered their knowledge met their requirements, who had no difficulty in finding diabetes-related information, who understood diabetes-related information well and were able to identify diabetes-related knowledge were defined as having good information acquisition and utilisation. Those who demonstrated good behaviour or good information acquisition and utilisation were given a score of 2 , and all others were given a score of 0. Questionnaire total scores ranged from 0 to 54 , with a score $>43.2$ indicating diabetes-related health literacy. ${ }^{23}$

\section{Anthropometric measurements}

Anthropometric measurements included blood pressure, height, weight and waist circumference. Blood pressure was assessed twice (2 min apart) using an electronic blood pressure monitor (Life Source UA-767PV, A\&D Medical, San Jose, California, USA) after the participant had been seated for at least $5 \mathrm{~min}$ in a quiet room. The two blood pressure readings were averaged to obtain a mean resting blood pressure for each participant. Hypertension is defined as systolic blood pressure $\geq 140 \mathrm{~mm} \mathrm{Hg}$ and/or diastolic pressure $\geq 90 \mathrm{~mm} \mathrm{Hg} .{ }^{24}$ Hypotension is defined as systolic blood pressure $<90 \mathrm{~mm} \mathrm{Hg}$ and/or diastolic pressure $<60 \mathrm{~mm} \mathrm{Hg} .{ }^{24}$

Height was measured to the nearest $0.1 \mathrm{~cm}$ using a stadiometer, and weight was measured without shoes and in light indoor clothing to the nearest $0.1 \mathrm{~kg}$. BMI was computed with the following formula: $\mathrm{BMI}=\mathrm{kg} / \mathrm{m}^{2}$. Participants were defined as being lean (BMI $<18.5$ ), normal $(18.5<$ BMI $<24.0)$, overweight $(24.0<$ BMI $<28.0)$ or obese $(\mathrm{BMI} \geq 28.0)$ according to Chinese standards. ${ }^{25}$

Waist circumference was measured to the nearest $0.1 \mathrm{~cm}$ by placing a non-stretching measuring tape horizontally around the participant's abdomen at the top of the iliac crest. The reading was taken after expiration while ensuring that the tape was secure but not too tight. Hip measurement was taken at the point of maximum circumference over the buttocks, with the measuring tape held horizontally and touching the 
surface of light clothing. The waist-to-hip ratio (WHR) was calculated by dividing the waist measurement by the hip measurement. WHR $>0.9$ in men and $>0.8$ in women was defined as abnormal WHR. ${ }^{26}$

\section{Statistical analysis}

The data were analysed using SPSS V.20.0 (SPSS/IBM, Armonk, New York, USA). Data are presented as the percentage, mean \pm SD, median and IQR. Non-parametric tests were used because the distribution of the health literacy scores on diabetes prevention and control was non-Gaussian. The Kruskal-Wallis test was used to explore differences in diabetes health literacy among individuals with prediabetes with different characteristics. The two-tailed significance threshold was set at $\mathrm{p}<0.05$ in these analyses.

Binary logistic regression analysis was performed to identify risk factors for low diabetes health literacy among the elderly with prediabetes. The median value was used to definite groups. The diabetes health literacy scores were selected as the dependent variables and classified into group 1 (score $>10.0$ ) and group 2 (score $\leq 10.0)$. Gender ( $1=$ female and $2=$ male), age ( $1=$ age $60-$ 64 years, $2=$ age $65-69$ years, $3=$ age $70-74$ years, $4=$ age $75-79$ years, $5=$ age $80-84$ years, and $6=$ age $\geq 85$ years), education ( $1=$ less than 1 year, $2=1-6$ years, and $3=6$ years and above), marital status ( $1=$ stable marital status and $2=$ unstable marital status), history of hyperglycaemia ( $1=$ yes and $2=$ no), family history of diabetes $(1=$ yes and $2=$ no), other chronic disease status $(1=$ yes and $2=$ no), BMI (1=lean, 2=normal, 3=overweight, and 4=obese), WHR ( $1=$ normal and 2=abnormal) and blood pressure ( $1=$ normal and $2=$ abnormal) were entered as independent variables. Step-wise logistic regression was conducted to analyse the risk factors for low diabetes health literacy using significance levels of 0.05 for entry and 0.10 for removal from the model.

\section{RESULTS}

The characteristic of the study population

A total of 42 villages were selected and 2144 subjects took part in the study. The prevalence of prediabetes was $21.5 \%(461 / 2144)$ and 434 individuals with prediabetes completed the questionnaire. The descriptive characteristics of the elderly subjects with prediabetes are given in table 1.

Individuals with the prediabetes were an average $( \pm \mathrm{SD})$ of $69.4( \pm 6.45)$ years of age. Men comprised $41.5 \%$ of participants. Most of the participants had a stable marital status $(\mathrm{n}=313,72.1 \%)$ and had a low level of education $(n=353,81.3 \%)$. There was no difference in educational level between men and women $(p>0.05)$.

Few participants had a history of hyperglycaemia $(\mathrm{n}=28,6.5 \%)$ or a family history of diabetes $(\mathrm{n}=36$, $8.3 \%)$. A total of $176(40.6 \%)$ participants had other chronic diseases, $29.7 \% \quad(\mathrm{n}=129)$ of participants were overweight and $12.7 \%(n=55)$ of them were obese. Most

\begin{tabular}{|c|c|c|}
\hline & $\mathbf{N}$ & Mean \pm SD or $\%$ \\
\hline Age & 434 & $69.4 \pm 6.45$ \\
\hline \multicolumn{3}{|l|}{ Gender } \\
\hline Male & 180 & 41.5 \\
\hline Female & 254 & 58.5 \\
\hline \multicolumn{3}{|l|}{ Marital status } \\
\hline Stable & 313 & 72.1 \\
\hline Unstable & 121 & 27.9 \\
\hline \multicolumn{3}{|l|}{ Education } \\
\hline Less than 1 year & 81 & 18.7 \\
\hline $1-6$ years & 272 & 62.6 \\
\hline 6 years and above & 81 & 18.7 \\
\hline \multicolumn{3}{|c|}{ History of hyperglycaemia } \\
\hline Yes & 28 & 6.5 \\
\hline No & 406 & 93.5 \\
\hline \multicolumn{3}{|c|}{ Family history of diabetes } \\
\hline Yes & 36 & 8.3 \\
\hline No & 398 & 91.7 \\
\hline \multicolumn{3}{|l|}{ Other chronic disease } \\
\hline Yes & 176 & 40.6 \\
\hline No & 258 & 59.4 \\
\hline \multicolumn{3}{|l|}{ BMI } \\
\hline Lean & 17 & 3.9 \\
\hline Normal & 233 & 53.7 \\
\hline Overweight & 129 & 29.7 \\
\hline Obese & 55 & 12.7 \\
\hline \multicolumn{3}{|l|}{ WHR } \\
\hline Normal & 77 & 17.7 \\
\hline Abnormal & 357 & 82.3 \\
\hline \multicolumn{3}{|l|}{ Blood pressure } \\
\hline Normal & 235 & 54.1 \\
\hline Abnormal & 199 & 45.9 \\
\hline \multicolumn{3}{|l|}{ Type of prediabetes } \\
\hline IFG & 186 & 42.9 \\
\hline IGT & 190 & 43.7 \\
\hline IFG+IGT & 58 & 13.4 \\
\hline
\end{tabular}

of the participants had abnormal WHR ( $\mathrm{n}=357,82.3 \%$ ), and nearly half of them had abnormal blood pressure $(45.9 \%, \mathrm{n}=199)$. More individuals had IGT $(\mathrm{n}=190$, $43.8 \%)$ than IFG $(n=186,42.9 \%)$ or IFG+IGT $(n=58$, $13.4 \%)$.

\section{Diabetes health literacy scores}

The health literacy scores for diabetes prevention and control of prediabetes are shown in table 2. The median score was 10.0 (IQR 7.0-13.0). Only one person demonstrated diabetes health literacy $(1 / 434)$.

Men had lower diabetes health literacy scores than women $(9.0$ vs $11.0, \mathrm{p}<0.05)$. The health literacy scores of elderly subjects with prediabetes in a stable marriage were higher than those in unstable marriages (10.0 vs $9.0, \mathrm{p}<0.05)$. Elderly individuals with prediabetes who had less than 1 year of education had the lowest health 
Table 2 Health literacy scores for diabetes prevention and prediabetes control

\begin{tabular}{|c|c|c|c|}
\hline & $\begin{array}{l}\text { Mean } \\
\pm \text { SD }\end{array}$ & Median (IQR) & $\begin{array}{l}\mathbf{p} \\
\text { Value }\end{array}$ \\
\hline Overall & $11.0 \pm 6.33$ & $10.0(7.0-13.0)$ & \\
\hline Age (years) & & & 0.553 \\
\hline $60-64$ & $12.1 \pm 7.2$ & $11.0(7.0-14.0)$ & \\
\hline $64-69$ & $11.2 \pm 6.7$ & $10.0(7.0-13.0)$ & \\
\hline $70-74$ & $10.6 \pm 6.6$ & $9.0(7.0-12.0)$ & \\
\hline $75-79$ & $10.4 \pm 4.3$ & $10.0(7.8-12.0)$ & \\
\hline $80-85$ & $9.4 \pm 3.9$ & $9.0(6.5-11.0)$ & \\
\hline$>85$ & $9.8 \pm 1.8$ & $10.0(8.5-11.3)$ & \\
\hline Gender & & & 0.000 \\
\hline Male & $10.3 \pm 7.17$ & $9.0(7.0-12.0)$ & \\
\hline Female & $11.5 \pm 5.63$ & $11.0(8.0-13.0)$ & \\
\hline Marital status & & & 0.044 \\
\hline Stable & $11.4 \pm 6.51$ & $10.0(7.0-13.0)$ & \\
\hline Unstable & $10.1 \pm 5.78$ & $9.0(7.0-11.0)$ & \\
\hline Education & & & 0.000 \\
\hline Less than 1 year & $7.7 \pm 2.55$ & $8.0(6.5-9.0)$ & \\
\hline $1-6$ years & $11.3 \pm 6.35$ & $11.0(7.0-13.0)$ & \\
\hline $\begin{array}{l}6 \text { years and } \\
\text { above }\end{array}$ & $13.2 \pm 7.57$ & $12.0(9.0-16.0)$ & \\
\hline $\begin{array}{l}\text { History of } \\
\text { hyperglycaemia }\end{array}$ & & & 0.001 \\
\hline Yes & $15.1 \pm 8.11$ & $12.5(9.3-20.5)$ & \\
\hline No & $10.7 \pm 6.10$ & $9.0(7.0-12.0)$ & \\
\hline $\begin{array}{l}\text { Family history of } \\
\text { diabetes }\end{array}$ & & & 0.165 \\
\hline Yes & $12.5 \pm 7.54$ & $12.0(7.0-13.8)$ & \\
\hline No & $10.9 \pm 6.20$ & $10.0(7.0-12.0)$ & \\
\hline $\begin{array}{l}\text { Other chronic } \\
\text { disease }\end{array}$ & & & 0.544 \\
\hline Yes & $11.5 \pm 7.08$ & $10.0(7.0-13.0)$ & \\
\hline No & $10.7 \pm 5.76$ & $10.0(7.0-13.0)$ & \\
\hline BMI & & & 0.547 \\
\hline Lean & $9.9 \pm 5.33$ & $9.0(5.5-13.5)$ & \\
\hline Normal & $10.7 \pm 5.95$ & $9.0(7.0-13.0)$ & \\
\hline Overweight & $11.9 \pm 7.52$ & $10.0(7.0-12.0)$ & \\
\hline Obese & $10.5 \pm 4.87$ & $10.0(7.0-13.0)$ & \\
\hline WHR & & & 0.074 \\
\hline Normal & $10.4 \pm 6.72$ & $9.0(7.0-12.0)$ & \\
\hline Abnormal & $11.2 \pm 6.25$ & $10.0(7.0-13.0)$ & \\
\hline Blood pressure & & & 0.978 \\
\hline Normal & $10.9 \pm 5.76$ & $10.0(7.0-13.0)$ & \\
\hline Abnormal & $11.2 \pm 6.96$ & $10.0(7.0-13.0)$ & \\
\hline Type of prediabetes & & & 0.451 \\
\hline IFG & $11.4 \pm 6.49$ & $10.0(7.0-13.0)$ & \\
\hline IGT & $10.6 \pm 6.09$ & 9.0 (7.0-12.3) & \\
\hline IFG+IGT & $11.2 \pm 6.65$ & $10.0(7.0-12.0)$ & \\
\hline
\end{tabular}

literacy scores compared to the other two educational levels ( 8.0 vs 11.0 vs $12.0, \mathrm{p}<0.05)$. The health literacy scores of elderly subjects with prediabetes and a history of hyperglycaemia were higher than those of subjects without a history of hyperglycaemia ( 12.5 vs $9.0, \mathrm{p}<0.05)$. There were no differences in the diabetes health literacy scores related to age, family history of diabetes, other chronic diseases, BMI, WHR, blood pressure or type of prediabetes $(\mathrm{p}>0.05)$.

\section{Risk factors for low diabetes health literacy scores}

The results of the binary logistic regression analysis of risk factors for low diabetes health literacy are shown in table 3 .

After controlling for gender, age, marital status, history of chronic disease, BMI, WHR, type of prediabetes and blood pressure, independent risk factors for low diabetes health literacy among elderly individuals with prediabetes were being male, not having a history of hyperglycaemia and have a low educational level. Elderly subjects with prediabetes who were male (OR $2.831,95 \%$ CI 1.818 to 4.408 ), did not have a history of hyperglycaemia (OR 2.676, 95\% CI 1.101 to 6.504 ), had less than 1 year of education (OR 31.148, 95\% CI 11.661 to 83.204 ) or $1-6$ years of education (OR $14.274,95 \%$ CI 5.927 to 34.375 ) were more likely to have lower diabetes health literacy.

\section{DISCUSSION}

\section{High prevalence of prediabetes among the rural elderly}

This study found a high prevalence of prediabetes among the rural elderly of $21.5 \%$, which is similar to the findings of an earlier study. ${ }^{27}$ As reported previously, the prevalence of prediabetes is rapidly increasing in China, especially in rural areas. ${ }^{42}$ These results together with the large population living in poor rural areas suggest an emerging serious public health problem in rural China. Diabetes can be prevented or delayed in individuals with prediabetes through appropriate interventions, so the rising prevalence of prediabetes and diabetes in rural China has highlighted a need for better prevention.

\section{Low diabetes health literacy among the rural elderly with prediabetes}

We used a health literacy questionnaire specific to diabetes prevention and control to measure health literacy among elderly individuals with prediabetes, unlike other studies which used general health literacy measures, such as STOFHLA or REALM, which are not disease or condition-specific. Our questionnaire was able to effectively examine the level of health literacy regarding diabetes prevention and control among subjects with prediabetes. ${ }^{23}$ Yamashita and $\mathrm{Kart}^{28}$ showed a direct association between diabetes-specific health literacy and patient assessments of their self-care ability and demonstrated that health literacy measures should include indicators of disease-specific knowledge and/or understanding. Thus, it is better to measure health literacy specific to diabetes prevention and control when assessing health literacy level regarding diabetes prevention and control among elderly subjects with prediabetes. Health literacy specific to diabetes prevention and control is crucial for diabetes management and 
Table 3 Results of binary logistic regression analysis of risk factors for low diabetes health literacy

\begin{tabular}{|c|c|c|c|c|c|}
\hline & 及 Coefficient & Wald test & p Value & OR & $95 \% \mathrm{Cl}$ \\
\hline \multicolumn{6}{|l|}{ Gender } \\
\hline Female & & & & 1.000 & \\
\hline Male & 1.041 & 21.225 & 0.000 & 2.831 & 1.818 to 4.408 \\
\hline \multicolumn{6}{|l|}{ Education } \\
\hline 6 years and above & & & & 1.000 & \\
\hline $1-6$ years & 2.658 & 35.148 & 0.000 & 14.274 & 5.927 to 34.375 \\
\hline Less than 1 year & 3.439 & 47.055 & 0.000 & 31.148 & 11.661 to 83.20 \\
\hline \multicolumn{6}{|c|}{ History of hyperglycaemia } \\
\hline Yes & & & & 1.000 & \\
\hline No & 0.984 & 4.722 & 0.030 & 2.676 & 1.101 to 6.504 \\
\hline
\end{tabular}

prevention. Thus, the questionnaire used here accurately reflected health literacy regarding diabetes prevention and control among elderly subjects with prediabetes.

The median diabetes health literacy score 10.0 (IQR 7.0-13.0); the lowest score was 1.0 and the highest score was 44.0. Only one person demonstrated diabetes-related health literacy, suggesting that such knowledge among elderly rural individuals with prediabetes is very limited. Our results are similar to previous findings. ${ }^{17} 2329 \mathrm{~A}$ survey using the same questionnaire and administered to 4282 residents aged $18-60$ years without diabetes in six Chinese provinces showed a low level of diabetes health literacy. ${ }^{23}$ The rate of diabetes health literacy was $20.7 \%$ among people with less than 1 year of education, and $18.7 \%$ among farmers in rural areas. ${ }^{23}$ Low health literacy is also associated with age, particularly among people aged 65 years or older. ${ }^{17} 29$ Thus, rural elderly patients with prediabetes who have a high risk of developing diabetes should be targeted for diabetes prevention as low health literacy is associated with poorer health outcomes. Diabetes health literacy is related to diabetes knowledge, self-efficacy, self-care behaviours, and glycaemic control.

\section{Risk factors for low diabetes health literacy among elderly rural individuals with prediabetes}

Understanding the positive and negative factors associated with diabetes health literacy is necessary for implementing preventive measures. In our study, the factors included several socio-demographic variables and a history of hyperglycaemia. Binary logistic regression revealed that risk factors for low diabetes health literacy among elderly individuals with prediabetes including being male, having a low level of education and not having a history of hyperglycaemia. These results are consistent with previous studies, ${ }^{17}{ }^{29}$ although the finding of hyperglycaemia is new to this study.

Men have lower diabetes health literacy than women, as reported in other countries. ${ }^{30-32}$ Health literacy is identified as a key health determinant because of its link to behavioural choices and service usage. ${ }^{33}$ The relationship between health literacy and unhealthy lifestyle behaviours (eg, tobacco use and harmful alcohol consumption) has been confirmed. ${ }^{34}{ }^{35}$ In many countries, men are more likely to engage in risky lifestyle behaviours, have lower health knowledge and pay less attention to preventative healthcare than women. In addition, women are more likely to care for sick family members ${ }^{36-38}$ than men and thus have more contact with the healthcare environment.

Education is an important factor with regard to health literacy. Some studies have found an association between education and health literacy components (eg, nutrition literacy, health knowledge and personal skills). ${ }^{34} 3940$ The level of evidence supporting a correlation between education and health literacy was rated as moderate; people with a high level of education had better health outcomes because of the mediating effect of health literacy. ${ }^{29}$

This is the first time that the relationship between a history of hyperglycaemia and diabetes-related health literacy has been analysed. We found that hyperglycaemia influenced diabetes health literacy. People with a history of hyperglycaemia had a higher level of diabetes health literacy, likely because they are concerned about developing diabetes and actively seek information on diabetes and behaviours. These results suggest that people with a high level of health literacy may have better glycaemic control, as indicated by previous studies. ${ }^{12} 41$ As reported, low health literacy is associated with a nearly twofold lower odds of good glycaemic control than high health literacy among patients with diabetes (adjusted OR $2.03,95 \%$ CI 1.11 to 3.73$).^{42}$

Health literacy also mediates the relationship between education and glycaemic control among low-income patients with diabetes. ${ }^{12} 43$ People with poor overall literacy may face challenges in writing and communicating. In particular, those with low health literacy are less likely to initiate and maintain successful diabetes care, which involves interactive communication and participatory decision-making. Elderly patients with prediabetes in poor rural areas have low diabetes health literacy, low educational levels and insufficient health education, and so may not look for effective or suitable resources. Because health literacy includes diabetes-specific 
knowledge, self-efficacy, self-care behaviours and glycaemic control, strategies to improve health literacy are urgently needed.

A limitation of this study is its cross-sectional design, and so causation cannot be inferred. Moreover, we cannot exclude that the self-reported design introduced bias, and so further studies are needed to confirm these findings.

\section{CONCLUSIONS}

Our study has revealed very low health literacy regarding diabetes prevention and control among an elderly population with prediabetes in poor rural areas of China. Being male, having a low educational level and not having a history of hyperglycaemia were risk factors for low diabetes health literacy among elderly individuals with prediabetes. Considering the high prevalence of prediabetes and diabetes in rural China and the low educational attainment, low income and old age of this population, future studies should evaluate appropriate measures for improving diabetes-related health literacy among these individuals.

Acknowledgements We would like to thank Fan Gao, Yang Yang, Fangfan Jiang, Ting Zhang and Zhao Hu who took part in this study as investigators.

Contributors $H X$ and $L Q$ wrote, checked and revised the manuscript.

Competing interests None declared.

Patient consent Obtained.

Ethics approval This study was approved by the IRB of the Chinese Clinical Trial Registry (No. ChiCTR-IOR-15007033).

Provenance and peer review Not commissioned; externally peer reviewed.

Data sharing statement No additional data are available.

Open Access This is an Open Access article distributed in accordance with the Creative Commons Attribution Non Commercial (CC BY-NC 4.0) license, which permits others to distribute, remix, adapt, build upon this work noncommercially, and license their derivative works on different terms, provided the original work is properly cited and the use is non-commercial. See: http:// creativecommons.org/licenses/by-nc/4.0/

\section{REFERENCES}

1. Abegunde DO, Mathers CD, Adam T, et al. The burden and costs of chronic diseases in low-income and middle-income countries. Lancet 2007;370:1929-38.

2. Wild S, Roglic G, Green A, et al. Global prevalence of diabetes: estimates for the year 2000 and projections for 2030. Diabetes Care 2004;27:1047-53.

3. Tian $\mathrm{H}$, Song $\mathrm{G}$, Xie $\mathrm{H}$, et al. Prevalence of diabetes and impaired fasting glucose among 769,792 rural Chinese adults. Diabetes Res Clin Pract 2009;84:273-8.

4. Yang W, Lu J, Weng J, et al. Prevalence of diabetes among men and women in China. N Engl J Med 2010;362:1090-101.

5. Tabák AG, Herder C, Rathmann W, et al. Prediabetes: a high-risk state for diabetes development. Lancet 2012;379:2279-90.

6. Knowler WC, Fowler SE, Hamman RF, et al., Diabetes Prevention Program Research Group. 10-Year follow-up of diabetes incidence and weight loss in the Diabetes Prevention Program Outcomes Study. Lancet 2009;374:1677-86.

7. International Diabetes Federation. IDF Diabetes Atlas, 6th edn. Brussels, Belgium: International Diabetes Federation, 2013. http:// www.idf.org/diabetesatlas.

8. American Diabetes Association. Economic costs of diabetes in the U.S. in 2007. Diabetes Care 2008;31:596-615.
9. Nielsen-Bohlman L, Panzer AM, Kindig DA, et al., Institute of Medicine (US) Committee on Health Literacy. Health Literacy: $A$ Prescription to End Confusion. Washington, USA: The National Academies Press, 2004:25-67.

10. Kutner M. The Health Literacy of America's Adults: Results from the 2003 National Assessment of Adult Literacy. NCES (Series). Washington, DC: United States Department of Education, National Center for Education Statistics. http://nces.ed.gov/pubs2006/ 2006483.pdf

11. Chen GD, Huang CN, Yang YS, et al. Patient perception of understanding health education and instructions has moderating effect on glycemic control. BMC Public Health 2014;14:683.

12. Schillinger D, Barton LR, Karter AJ, et al. Does literacy mediate the relationship between education and health outcomes? A study of a low-income population with diabetes. Public Health Rep 2006;121:245-54.

13. Kolb JM, Kitos NR, Ramachandran A, et al. What do primary care prediabetes patients need? A baseline assessment of patients engaging in a technology-enhanced lifestyle intervention. $J$ Bioinform Diabetes 2014;1:4.

14. Rosa MC, Benjamin EM, Peko PS, et al. Opportunities and challenges for diabetes prevention at two community health centers. Diabetes Care 2008;31:247-54.

15. Han HR, Kim J, Kim MT, et al. Measuring health literacy among immigrants with a phonetic primary language: a case of Korean American women. J Immigr Minor Health 2011;13:253-9.

16. Williams MV, Baker DW, Parker RM, et al. Relationship of functional health literacy to patients' knowledge of their chronic disease. A study of patients with hypertension and diabetes. Arch Intern Med 1998;158:166-72

17. Choi SE, Rush E, Henry S. Health literacy in Korean immigrants at risk for type 2 diabetes. J Immigr Minor Health 2013;15 553-9.

18. [No authors listed]. Health Literacy: Report of the Council on Scientific Affairs. Ad Hoc Committee on Health Literacy for the Council on Scientific Affairs, American Medical Association. JAMA 1999;281:552-7.

19. Rothman RL, DeWalt DA, Malone R, et al. Influence of patient literacy on the effectiveness of a primary care-based diabetes disease management program. JAMA 2004;292:1711-16.

20. Rothman $\mathrm{R}$, Malone $\mathrm{R}$, Bryant $\mathrm{B}$, et al. The relationship between literacy and glycemic control in a diabetes disease-management program. Diabetes Educ 2004;30:263-73.

21. U.S. Department of Health and Human Services. http://www. healthypeople.gov

22. Department of Noncommunicable Disease Surveillance. Definition, diagnosis and classification of diabetes mellitus and its complications: report of a WHO consultation. Part 1. Diagnosis and classification of diabetes mellitus. Geneva: World Health Organization, 1999. http://www.staff.ncl.ac.uk/philip.home/who_dmg. pdf (accessed 26 Feb 2010)

23. Li L, Li Y, Nie X, et al. An analysis of health literacy about diabetes prevention and control and its influencing factors among the residents in six provinces in China. Zhonghua Yu Fang Yi Xue Za Zhi 2014;48:561-5 [in Chinese].

24. Writing group of 2010 Chinese guidelines for the management of hypertension. 2010 Chinese guidelines for management of hypertension. Chin J Hypertens 2011;18:701-43 [in Chinese].

25. Health industry standard of the people's Republic of China. WS/T 428-2013.

26. Obesity in Asia Collaboration. Is central obesity a better discriminator of the risk of hypertension than body mass index in ethnically diverse populations? J Hypertens 2008;26:169-77.

27. $\mathrm{Xu} \mathrm{Y,} \mathrm{Wang} \mathrm{L,} \mathrm{He} \mathrm{J,} \mathrm{et} \mathrm{al.} \mathrm{Prevalence} \mathrm{and} \mathrm{control} \mathrm{of} \mathrm{diabetes} \mathrm{in}$ Chinese adults. JAMA 2013;310:948-59.

28. Yamashita T, Kart CS. Is diabetes-specific health literacy associated with diabetes-related outcomes in older adults? J Diabetes 2011;3:138-46.

29. Davey J, Holden CA, Smith BJ. The correlates of chronic disease-related health literacy and its components among men: a systematic review. BMC Public Health 2015;15:589.

30. Barber MN, Staples M, Osborne RH, et al. Up to a quarter of the Australian population may have suboptimal health literacy depending upon the measurement tool: results from a population-based survey. Health Promot Int 2009;24:252-61.

31. von Wagner C, Steptoe A, Wolf MS, et al. Health literacy and health actions: a review and a framework from health psychology. Health Educ Behav 2009;36:860-77.

32. Sudore RL, Mehta KM, Simonsick EM, et al. Limited literacy in older people and disparities in health and healthcare access. J Am Geriatr Soc 2006;54:770-6. 
33. Australian Commission on Safety and Quality in Health Care. Health literacy: taking action to improve safety and quality. Sydney: ACSQHC, 2014.

34. Aihara Y, Mina J. Barriers and catalysts of nutrition literacy among elderly Japanese people. Health Promot Int 2011;26:421-31.

35. Suka M, Odajima T, Okamoto M, et al. Relationship between health literacy, health information access, health behavior, and health status in Japanese people. Patient Educ Couns 2015;98:660-8.

36. Thompson RL, Lewis SL, Murphy MR, et al. Are there sex differences in emotional and biological responses in spousal caregivers of patients with Alzheimer's disease? Biol Res Nurs 2004;5:319-30.

37. Covinsky KE, Eng C, Lui LY, et al. Reduced employment in caregivers of frail elders: impact of ethnicity, patient clinical characteristics, and caregiver characteristics. J Gerontol A Biol Sci Med Sci 2001:56:M707-13.

38. Wallace Williams S, Dilworth-Anderson P, Goodwin PY. Caregiver role strain: The contribution of multiple roles and available resources in African-American women. Aging Ment Health 2003;7:103-12.
39. Lutfiyya MN, Lipsky MS, Bales RW, et al. Disparities in knowledge of heart attack and stroke symptoms among adult men: an analysis of behavioral risk factor surveillance survey data. J Natl Med Assoc 2008;100:1116-24.

40. Sohn M, Stotts NA, Benowitz N, et al. Beliefs about health, smoking, and future smoking cessation among South Korean men hospitalized for cardiovascular disease. Heart Lung 2007;36:339-47.

41. Osborn CY, Bains SS, Egede LE. Health literacy, diabetes self-care, and glycemic control in adults with type 2 diabetes. Diabetes Technol Ther 2010;12:913-19.

42. Schillinger D, Grumbach K, Piette J, et al. Association of health literacy with diabetes outcomes. JAMA 2002;288: 475-82.

43. Chaturvedi N, Stephenson JM, Fuller JH. The relationship between socioeconomic status and diabetes control and complications in the EURODIAB IDDM Complications Study. Diabetes Care 1996;19:423-30. 